\title{
Gold Nanoparticles/Thermochromic Composite Film on Screen-Printed Electrodes for Simultaneous Detection of Protein and Temperature
}

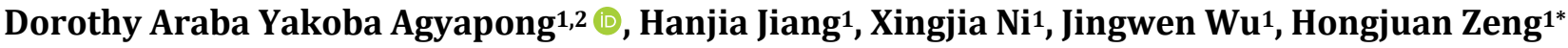 \\ ${ }^{1}$ School of Life Science and Technology, University of Electronic Science and Technology of China, Chengdu, China \\ ${ }^{2}$ Biomedical Engineering Program, Kwame Nkrumah University of Science and Technology, Kumasi, Ghana \\ Email: zenghj@uestc.edu.cn
}

How to cite this paper: Agyapong, D.A.Y., Jiang, H.J., Ni, X.J., Wu, J.W. and Zeng, H.J. (2021) Gold Nanoparticles/Thermochromic Composite Film on Screen-Printed Electrodes for Simultaneous Detection of Protein and Temperature. Journal of Biomaterials and Nanobiotechnology, 12, 7-19. https://doi.org/10.4236/jbnb.2021.121002

Received: February 21, 2021

Accepted: April 19, 2021

Published: April 22, 2021

Copyright $\odot 2021$ by author(s) and Scientific Research Publishing Inc. This work is licensed under the Creative Commons Attribution International License (CC BY 4.0).

http://creativecommons.org/licenses/by/4.0/

\begin{abstract}
In this study, gold nanoparticles and thermochromic composite films modified screen-printed carbon electrodes (TM-AuNPsSPCEs) were developed as a platform for the simultaneous detection of protein and temperature. The TM-AuNPs composited film had better sensitivity resulting from the gold nanoparticles amplification effect. A phase transition model analysis of TMAuNPs films found that the TM-AuNPs films had three-phase transition intervals $\left(<45^{\circ} \mathrm{C}, 45^{\circ} \mathrm{C}\right.$ to $80^{\circ} \mathrm{C}$ and $\left.>80^{\circ} \mathrm{C}\right)$ which accommodated the temperature requirements for protein denaturation. When used to detect different concentrations of haemoglobin $(\mathrm{Hb})$ solution, the TM-AuNPs modified SPCEs had a better sensitivity in detecting the different concentrations in comparison to TM and AuNP modified SPCEs which showed no clear sensitivity towards the different $\mathrm{Hb}$ concentrations. The dual detection and excellent sensitivity show a good application prospect for the study of the TM-AuNPs composite film.
\end{abstract}

\section{Keywords}

Screen-Printed Carbon Electrodes, Gold Nanoparticles, Thermochromic Material, Simultaneous Detection of Proteins and Temperature

\section{Introduction}

Gold nanoparticles (AuNPs) have been widely applied in diagnostics, therapy, prophylaxis, and hygiene since the discovery of immunogold labelling by Faulk and Taylor in the 1970s [1]. AuNPs have also been used in the development of 
protein biosensors [2] [3] [4]. Proteins exist in all organisms and are very important biological macromolecules. It is the executor of biological functions and plays a variety of physiological functions such as biocatalysis, material transport, movement, defense, regulation, memory, and recognition [5] [6] [7]. A very important condition for protein to realize these functions is to keep the environment at a certain temperature. With a change in temperature, some functions cannot be achieved because of changes in protein content and structure. In the last two decades, the research on the effect of temperature on protein mainly focused on thermal modification [8], denaturation, and stability [9] [10]. Heat treatment can make changes in the physical and chemical properties of proteins. The size, morphology, and interface of the heat-induced aggregate directly affect the functional properties of the gel, solubility, foaming, and emulsifying properties of the protein, thus affecting the quality of the protein-rich food and protein-based biopharmaceutics. For instance, Narhi et al. [11] found that increasing protein concentration increased the rate of protein aggregation during thermal treatment. This effect shows that the quantitative analysis of factors affecting protein aggregation such as detecting protein concentration at different temperatures and time is very important. In these studies, the protein content at different temperatures was detected by collecting the samples containing protein heated at different temperatures and time and then detecting the protein content of the processed samples using an optical instrument [12] [13]. The simultaneous and real-time detection of protein content under temperature changes has seldom been researched, due to the restriction of some key technical issues. Thereby, making it is difficult to detect the effect of temperature and time on protein content in real-time.

In this study, the surface of screen-printed electrodes was modified with gold nanoparticles and thermochromic composite film for the sensing of protein and temperature in real-time. SPCEs have been widely employed to develop electrochemical sensing platforms [12]. SPEs are less costly to produce and so can be made disposable, which is desirable when testing biological samples to help prevent surface fouling complications [13]. Disposable biosensors, made from screen-printed electrodes [14] [15] have led to novel prospects in detection and quantization. The SPCE surface can be modified easily to fit multiple purposes in relation to different analytes to achieve an assortment of improvements [16]. Gold nanoparticles (AuNPs) and thermochromic materials have both attracted considerable attention owing to their wide applications [17] [18] [19]. AuNPs when modified on SPEs provide them with a signal amplification property that can be applied in biosensing [20]. Thermochromic materials usually change color with a change in temperature [21]. These compounds are increasingly becoming hotspots for their many applications which include temperature-indicating devices, smart dyes, temperature-sensitive light filters, optical switching as well as imaging systems [22] [23].

In this work, TM-AuNPs composite film was first prepared by a simple method. The characterization of the TM-AuNPs modified electrode was performed 
using emission scanning electron microscopy (SEM), ultraviolet visible spectrum, and electrochemical cyclic voltammetry (CV). Owing to gold nanoparticles amplification effect between TM and SPCEs, enhanced voltammetric peaks at the TM-AuNPsSPCEs. Moreover, the proposed electrode was applied for the simultaneous determination of protein and temperature.

\section{Experimental}

\subsection{Chemicals and Reagents}

Bovine haemoglobin (BHb) solutions were acquired from Bio-cell Biotech. Co. Ltd. (Zhengzhou, China). Tetrachloroauric acid $\left(\mathrm{HAuCl}_{4} \cdot 4 \mathrm{H}_{2} \mathrm{O}\right)$ and trisodium citrate dihydrate $\left(\mathrm{Na}_{3} \mathrm{C}_{6} \mathrm{H}_{5} \mathrm{O}_{7} \cdot 2 \mathrm{H}_{2} \mathrm{O}\right)$ were obtained from Sinopharm Chemical Reagent Co. Ltd. (Shanghai, China). All other reagents were obtained from the First Reagent Factory (Shanghai, China).

\subsection{Sample Preparation}

\subsubsection{Gold Nanoparticle Synthesis}

The synthesis of gold nanoparticles was carried out according to the chemical reduction method using sodium citrate as a reducing agent [24]. Gold precursor (chloroauric acid $\left(\mathrm{Au}^{3+}, \mathrm{HAuCl}_{4}\right)$ ) was reduced to neutral gold $\left(\mathrm{Au}^{0}\right)$ using sodium citrate. Briefly, $100 \mathrm{~mL}$ of $0.01 \%(\mathrm{w} / \mathrm{v})$ chloroauric acid aqueous solution was brought to boil with good stirring. $2 \mathrm{~mL}$ of $1 \%$ trisodium citrate solution was then added rapidly with continuous stirring. The color changed from yellow-orange to red wine. The solution was boiled for about $15 \mathrm{~min}$ after the color change and then cooled and stored at $4{ }^{\circ} \mathrm{C}$ for future use. Sodium citrate deoxidized the $\mathrm{Au}$ ions to $\mathrm{Au}$ atoms which aggregated into nanoscale AuNPs while the citrate ions combined with the surface of nanogold particles as ligands. The anions covered the surface which prevented collision among particles and made it less prone to aggregation (Zhang et al., 2009).

\subsubsection{Thermochromic Material Preparation}

Four percent (4\%) PVA solution was prepared from $2 \mathrm{~g}$ PVA and $50 \mathrm{ml}$ distilled water. This solution was heated at $85^{\circ} \mathrm{C}$ with constant stirring for about an hour until the PVA was totally dissolved and allowed to cool at room temperature. 0.4 $\mathrm{g}$ of boric acid and $0.2 \mathrm{~g}$ of $\mathrm{NaOH}$ (ratio of 2:1) were dissolved with $10 \mathrm{ml}$ distilled water to prepare the borate buffer. Also, $0.001 \mathrm{~g}$ of cresol red as a color indicator was dissolved in $1 \mathrm{ml}$ ethanol and $5 \mathrm{ml}$ distilled water. The boric acid buffer solution earlier prepared, together with $0.03 \mathrm{~g} \mathrm{MgCl}_{2}$, was added with constant stirring. Finally, the "new" solution was slowly added to the cooled PVA solution earlier prepared and stirred continuously to form the thermochromic material.

\subsection{SPCE Modification}

\subsubsection{AuNPs-Modified SPCE}

Screen-printed carbon electrodes were purchased from DropSens-Llanera (As- 
turias, Spain). The bare SPCE comprised of a $3 \mathrm{~mm}$ diameter working electrode, a carbon counter electrode and a silver pseudo reference electrode. The working electrode surface of SPCE was modified with AuNPs, using electrochemical deposition method. The surface of the SPCE was washed with ultrapure water prior to deposition. The working electrode was then activated in phosphate-buffered saline (PBS) $(\mathrm{pH}=6.8)$ for $45 \mathrm{~s}$ (at $2 \mathrm{~V}$ ) at room temperature using the current-time method to further clean the electrodes. It was then put in the nanogold solution and connected to the electrochemical workstation via its interface. The electrodeposition was run for 2 hours with $+1.5 \mathrm{~V}$ deposition potential. The electrode was washed with ultrapure water after the deposition.

\subsubsection{Preparation of TM-AuNPs Modified SPCE}

The thermochromic material (TM) was incubated on the AuNPs-modified working electrode of SPCE to make a highly sensitive electrochemical sensor for soluble protein detection. The thermochromic material was immobilized onto the working electrode and allowed to stand for 24 hours at room temperature. From experience after repeated experiments, incubating the thermochromic material for 24 hours formed a uniform film on the electrode.

\subsubsection{SEM Characterization and Electrochemical Measurement}

The morphology of the as-prepared AuNPs and TM-AuNPs films was characterized using scanning electron microscopy (SEM, HITACHI S-4800). All electrochemical measurements were carried out with an electrochemical workstation (CHI 660 D, U.S.A). The electrochemical measurements were performed in the electrolyte solution of $2.5 \mathrm{mM} \mathrm{K}_{4}\left[\mathrm{Fe}(\mathrm{CN})_{6}\right]+2.5 \mathrm{mM} \mathrm{K}_{3}\left[\mathrm{Fe}(\mathrm{CN})_{6}\right]$ with either constant or varying concentrations of $\mathrm{Hb}$ at either constant or varying temperatures using four different working electrodes; unmodified-SPCEs (bare), AuNPsSPCE, TM-SPCEs and TM-AuNPs-SPCEs.

\section{Results and Discussion}

\subsection{Design Strategy of the Dual Protein and Temperature Biosensor}

The fabrication procedure of temperature and $\mathrm{Hb}$ protein biosensing alternative dual platforms was shown in Figure 1. A thin layer of AuNPs with negative charge was electrodeposited on the surface of SPCE substrate and a thin TM film with positive charge was immobilized on the surface of AuNPs via electrostatic interaction Figure 1(a). Electrochemical techniques were used to investigate the response of AuNPs-SPCEs and TM-SPCEs and TM-AuNPs SPCEs by the measurement current before and after under different temperature and $\mathrm{Hb}$ solutions with different concentrations Figure 1(b). Since AuNPs nanoparticle with higher specific surface area could be bound with many positive charges in TM films, this improved the combination of positive charge TM film with negative $\mathrm{Hb}$. As a result, there was significant amplification in the response signal in contrast to when there was no AuNPs on the surface of TM-SPCEs. 


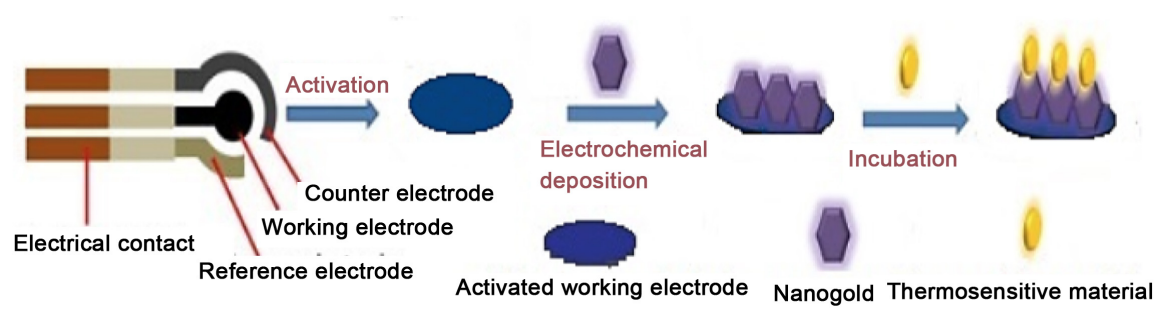

(a)

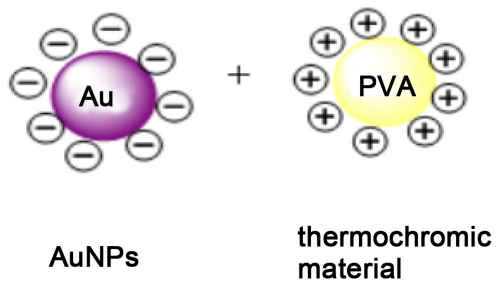

$\odot$ acid group anion

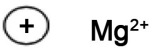

(b)

Figure 1. Functionalization modified SPCE for dual protein and temperature detection (a). Interaction between AuNPs and thermochromic material (b).

\subsection{The Thermochromic Mechanism from UV Spectra}

The thermochromic material was synthetized by the addition of boric acid to polyvinyl alcohol solution, which made the polyvinyl alcohol molecules cross linked and consequently formed a viscous elastic sticky polymer. The color of the thermochromic material changed with temperature due to the activity of lone pair electrons in oxygen atoms combined with the unoccupied orbital in boron atoms to form coordinate covalent bonds with cresol red molecule. This reaction was affected by temperature. At room temperature, cresol red contains a lactone ring structure and the color is jujube red. With an increase in temperature (up to $60^{\circ} \mathrm{C}$ ), the carbon-oxygen bond cleavage and the lactone ring is broken, electron transfer reactions occur to form negatively charged oxygen ions and positively charged carbon ions. The carbocations become stable by the $\mathrm{P}$-carbocation formation of $\pi$-conjugated structures through electron transfer, molecular re-arrangement and conjugated double bond transfixion and also the negative oxygen ions become sulfonic acid group anions. As these two ions can exist stably at high temperatures, the cresol red turns from lactone to quinone and the color changes to coffee brown. UV spectra (Figure 2) were used to detect its color change at different temperatures. The maximum absorption occurred in the range of $350-700 \mathrm{~nm}$ as a result of a better solubility of the cresol red at $55^{\circ} \mathrm{C}$ than at the other temperatures. Furthermore, a blue shift of $12 \mathrm{~nm}$ from $367 \mathrm{~nm}$ to $355 \mathrm{~nm}$ at $55^{\circ} \mathrm{C}$ can be found indicating the generation of electron transfer. The carbocations became stable by the P-carbocation formation of 


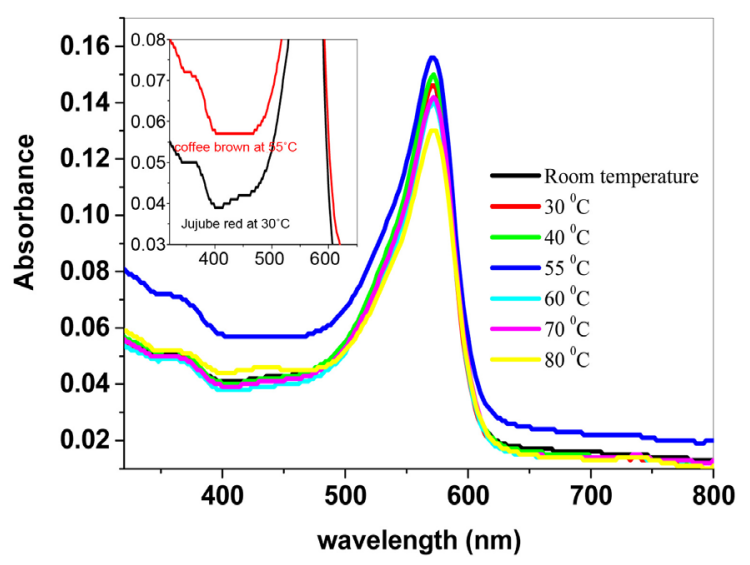

(a)<smiles>Cc1cc(C(OS(=O)(=O)c2ccccc2)(c2ccc(O)c(C)c2)c2ccc(O)c(C)c2)ccc1O</smiles>

Jujube red<smiles></smiles>

Coffee brown

(b)

Figure 2. UV spectra of thermochromic material at different temperature (a) cresol red discoloration effect (b).

$\pi$-conjugated structures through electron transfer, molecular re-arrangement and conjugated double bond transfixion and also the negative oxygen ions becoming sulfonic acid group anions. As these two ions exist stably at a high temperature, the cresol red changes from lactone to quinone and the color subsequently changed to coffee brown. With a temperature decrease, the quinone pi-conjugated structure becomes unstable, causing the conjugated double bond to fracture and a molecular re-arrangement leading to a relatively stable lactone structure being formed leading to a closed loop. The lactone structure and the quinone structures of cresol red are isomers to each other. In the whole reaction, the electron is given and received reversibly along with the change in temperature. The cresol red, therefore, exhibited reversible thermochromism [21]. Its thermochromic reaction is as shown in Figure 2(a) inset and Figure 2(b).

\subsection{The Effect of Heating on Morphology of TM-AuNPs and TM}

As may be observed, the morphology of the thermosensitive as-deposited (Figure 3(a)) and heat treated at $60^{\circ} \mathrm{C}$ (Figure 3(b)) showed a more regular TM-AuNPs deposition with better dispersion. The TM surface showed an amorphous surface (Figure 3(c)) at room temperature, but a uniform granular distribution of TM was observed on the surface after heat treatment (Figure $3(d))$. 

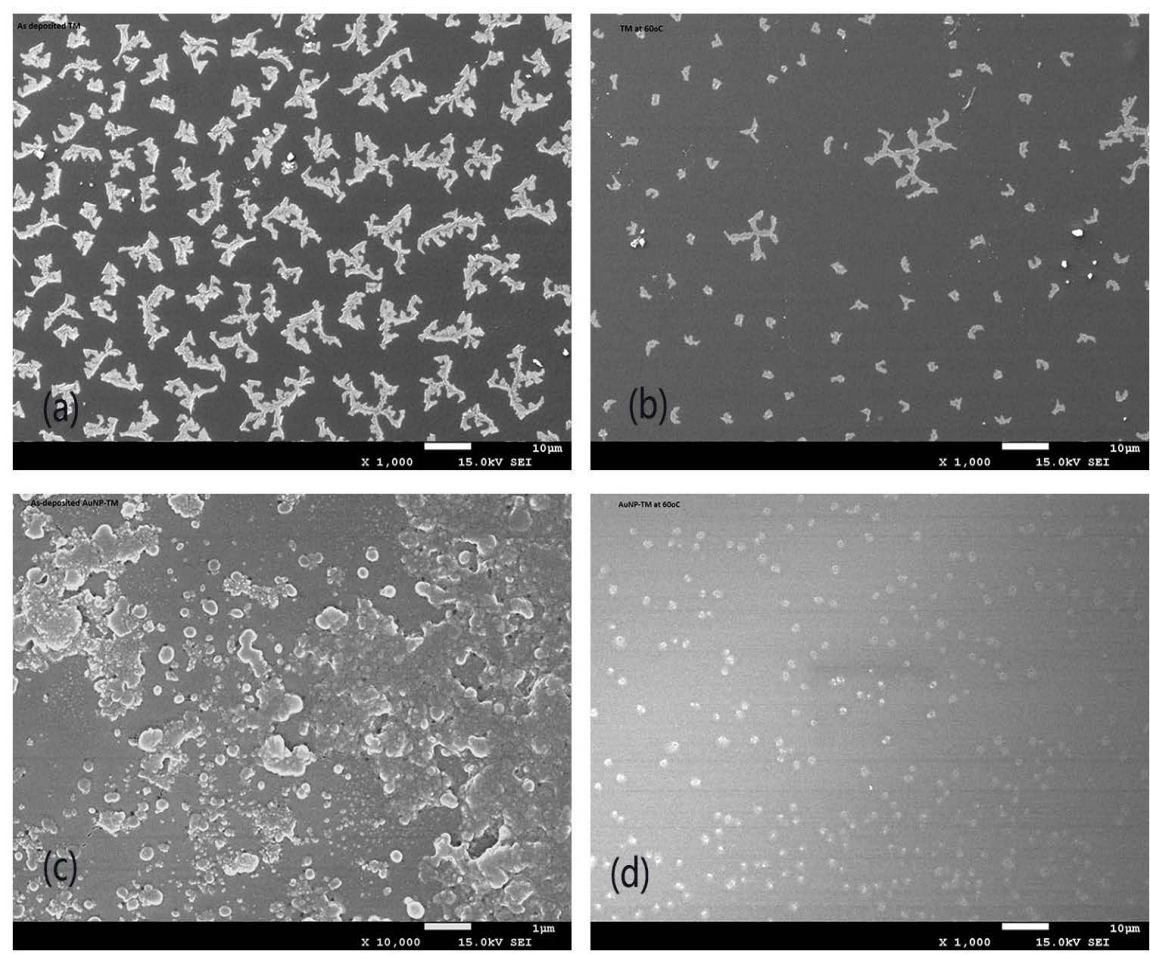

Figure 3. SEM images of the TM-AuNPsat room temperature (a), heat-treated at $60^{\circ} \mathrm{C}$ (b), TM at room temperature (c) and heat-treated TMat $60^{\circ} \mathrm{C}(\mathrm{d})$.

\subsection{Cyclic Voltametric Response of AuNPs, TM and TM-AuNPs Modified SPCE}

The cyclic voltametric electrochemical measurements of the AuNPs, TM, and TM-AuNPs modified SPCE at different temperatures were performed in an electrolyte solution of $2.5 \mathrm{mM} \mathrm{K}_{4}\left[\mathrm{Fe}(\mathrm{CN})_{6}\right]+2.5 \mathrm{mM} \mathrm{K}_{3}\left[\mathrm{Fe}(\mathrm{CN})_{6}\right]$. The characteristics of the bare SPCE, AuNPs and TM-AuNPs modified surfaces are shown in Figures 4(a)-(c). A lesser current response with no distinct paired peaks is seen in the bare electrode (Figure 4(a)). The lack of distinct paired peaks indicated that the bare electrode had a resistive surface that was not sensitive to temperature. When the SPCE surface was modified with the TM, the peak current response was almost twice that of the bare electrode at the same temperature range indicating that the TM was more sensitive to temperature than the bare surface (Figure $4(\mathrm{c})$ ). On the other hand, the TM-AuNPs modified SPCE, showed a peak current response more than three times that of the bare electrodes (Figure 5). Again, in comparison to the bare electrode, the biological sensitivity of the AuNP-modified SPCE was greatly improved (the peak current increased to almost six times that of the bare electrode) and had noticeable redox peaks [25]. The AuNPs, acted as a single amplifying quantum dot and resulted in improved biological sensitivity by amplifying the current (Figure 4(b)).

A phase transition model of the TM and TM-AuNPs films (Figure 5) was set up according to the ratio of reductive peak current of TM and TM-AuNPs films to AuNPs respectively. It showed the TM and TM-AuNPs films had same phase 


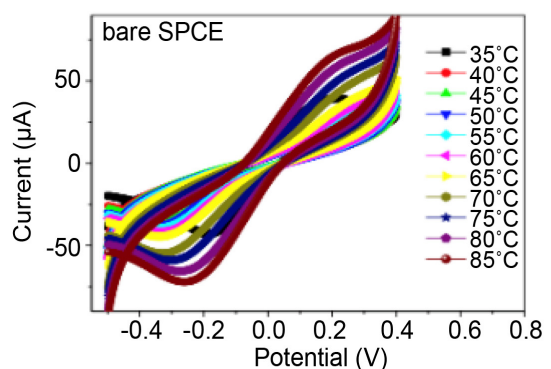

(a)

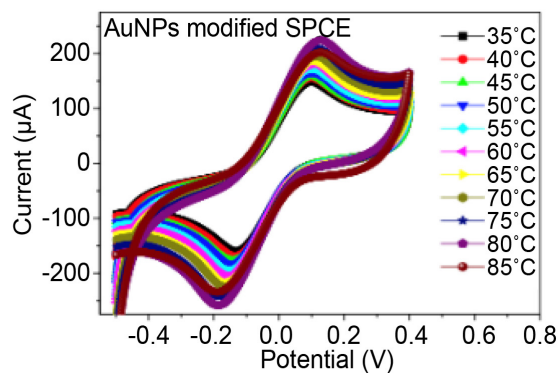

(b)

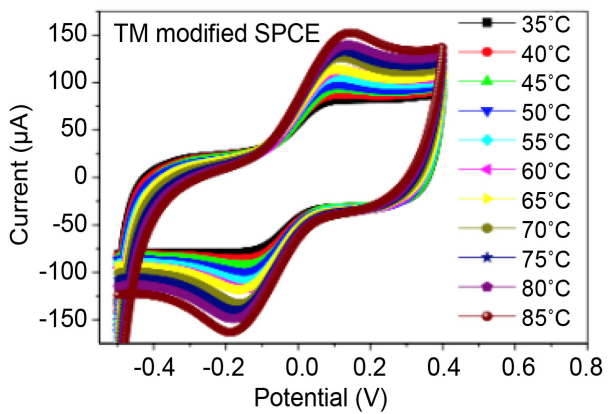

(c)

Figure 4. Cyclic voltametric curves of the bare SPCE (a), AuNP modified (b), TM modified (c), and (d) TM-AuNPs films at different temperatures (from $35^{\circ} \mathrm{C}$ to $85^{\circ} \mathrm{C}$ ).
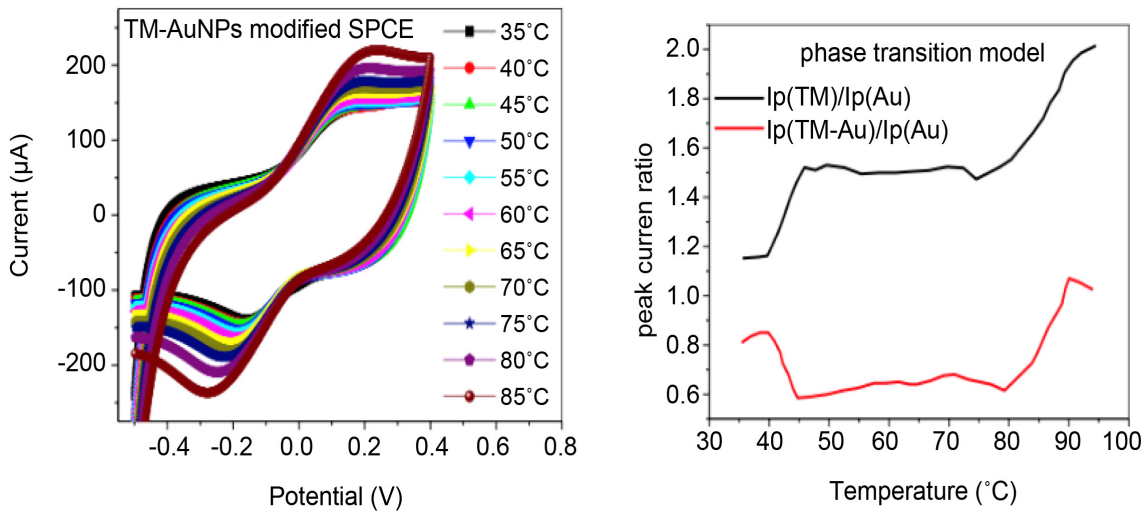

Figure 5. Phase transition model of TM and TM-AuNPs.

transition intervals; at $<45^{\circ} \mathrm{C}, 45^{\circ} \mathrm{C}$ to $80^{\circ} \mathrm{C}$, and $>80^{\circ} \mathrm{C}$, which accommodated the temperature requirements for protein denaturation [26] [27].

\subsection{Fabrication of AuNP-TM Composite Film and Protein Detection}

The AuNP-TM modified SPCE was also used to detect $0.2 \times 10^{-3} \mathrm{mmol} / \mathrm{L}$ hemoglobin $(\mathrm{Hb})$ solution and the $\mathrm{CV}$ is as shown in Figure 6. In comparison to the TM modified electrode, the biological sensitivity of the AuNP modified SPCE was greatly improved and had noticeable redox peaks [26]. The AuNPs, acting as a single amplifying quantum dot, improved the biological sensitivity by amplifying the current in AuNP-TM composite film. This shows that the AuNPTM composite film was successfully fabricated. 


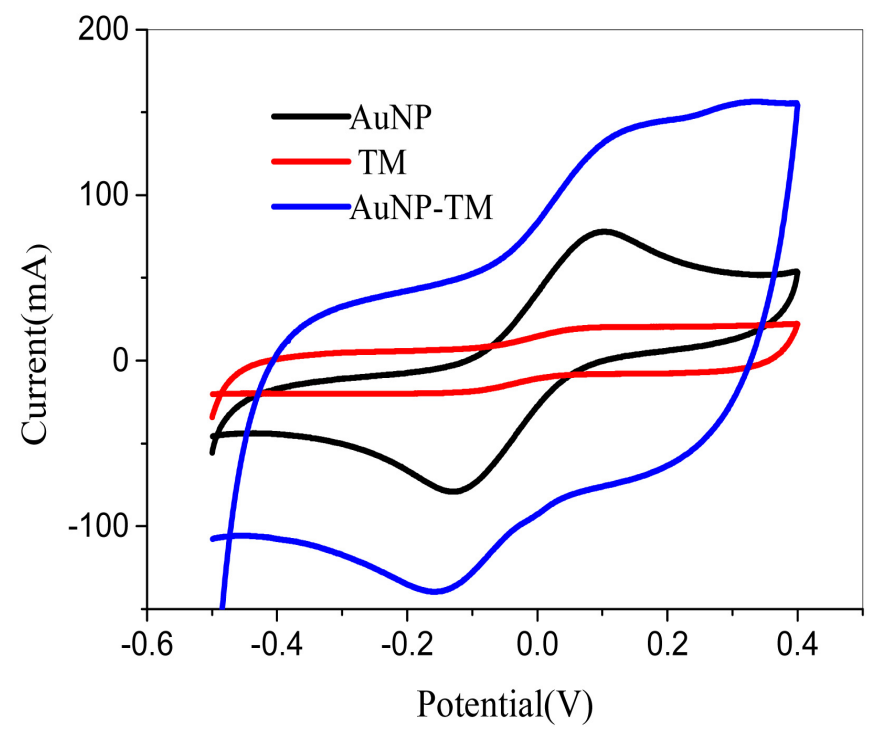

Figure 6. Cyclic voltammetry curves of $0.2 \times 10^{-3} \mathrm{mmol} / \mathrm{L} \mathrm{Hb}$ solution of AuNPs modified SPCE (black), TM modified SPCE (red), and AuNP-TM modified SPCE (blue).

\subsection{TM-AuNPs Modified SPCE for the Detection of Proteins at Different Temperatures}

To investigate the thermosensitivity and viability of the TM-AuNPs modified SPCE sensor, $2 \times 10^{-7} \mathrm{M}$ hemoglobin $(\mathrm{Hb})$ solution at different temperatures were studied using cyclic voltammetry. The variations in temperature were successfully detected by the sensor, indicating the applicability of the TM-AuNPs modified SPCE as a temperature sensor for proteins. The cyclic voltammetry curve (Figure 7) of the TM-AuNPs modified electrode under different temperatures for testing $\mathrm{Hb}$ solution $\left(2 \times 10^{-7} \mathrm{M}\right)$ showed that the current increased with increasing temperature after $30^{\circ} \mathrm{C}$, with the largest increase being observed in the temperature range of between $50^{\circ} \mathrm{C}-60^{\circ} \mathrm{C}$.

\subsection{TM-AuNPs Modified SPCE for the Detection of Proteins at Different Concentrations}

The TM-AuNPs modified sensor, was used to detect different concentrations of $\mathrm{Hb}$ solution at a constant temperature of $60^{\circ} \mathrm{C}$. The cyclic voltammetry curves and the differential pulse voltammograms (DPV) of TM-AuNPs modified SPCE (Figure 8) showed better sensitivity in detecting the different $\mathrm{Hb}$ concentrations. Using the DPV technique, at peak position (potential at $0 \mathrm{~V}$ ), it was observed that a linear relationship existed between the peak current and the log of the concentration in the range from -4 to -7 with $\mathrm{R}^{2}=0.99745$ and a linear fitting equation (inset in Figure 8(b)). The peak current increased with increase in concentration.

$$
\text { Ip }=-60.398+0.581 \log \left(\mathrm{CHь}_{\mathrm{H}}\right)
$$

where Ip denotes the peak current and $\mathrm{C}_{\mathrm{Hb}}$ is the concentration of haemoglobin. 

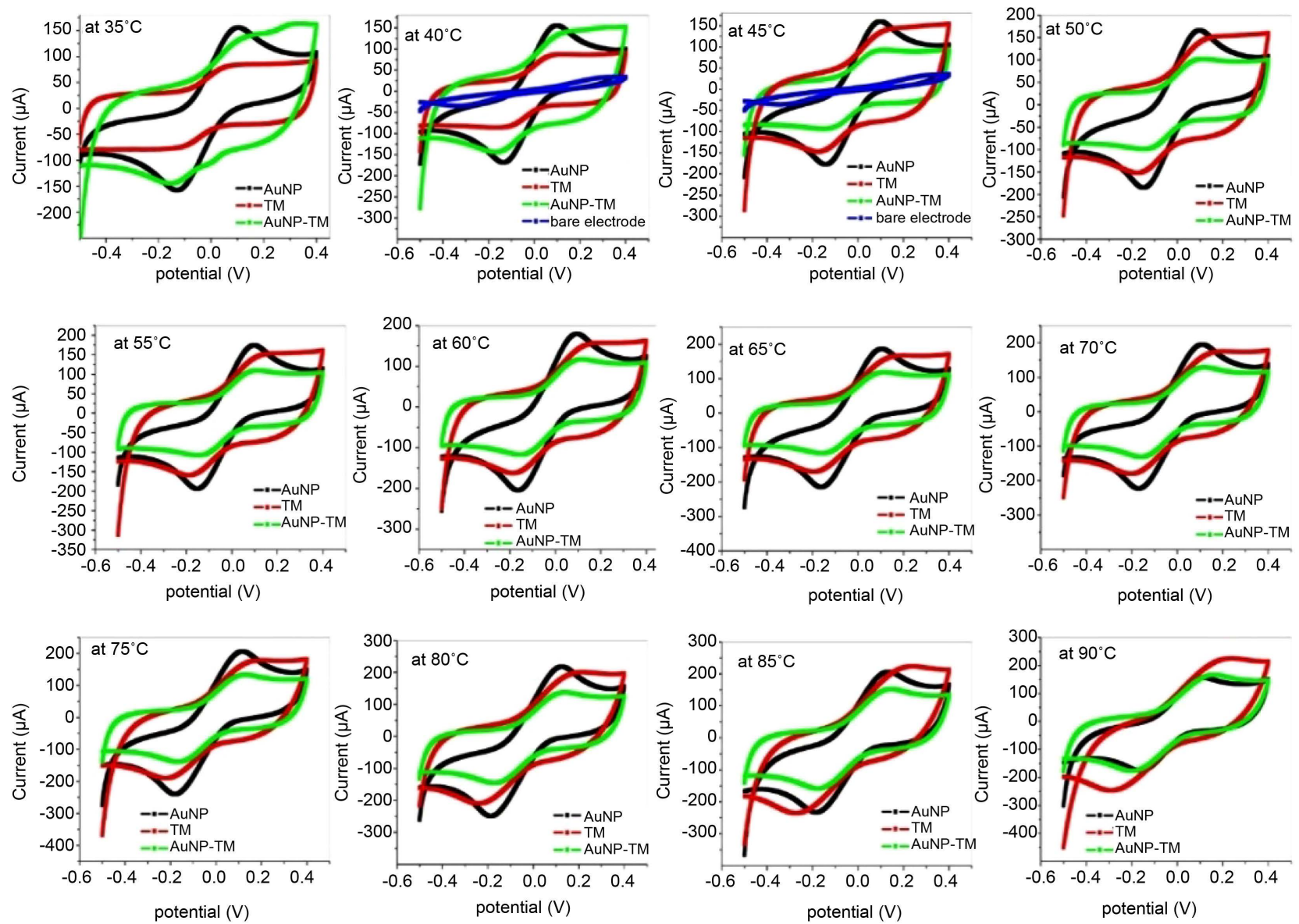

Figure 7. Cyclic voltammetry curves of AuNP-TM modified SPCE under different temperatures.
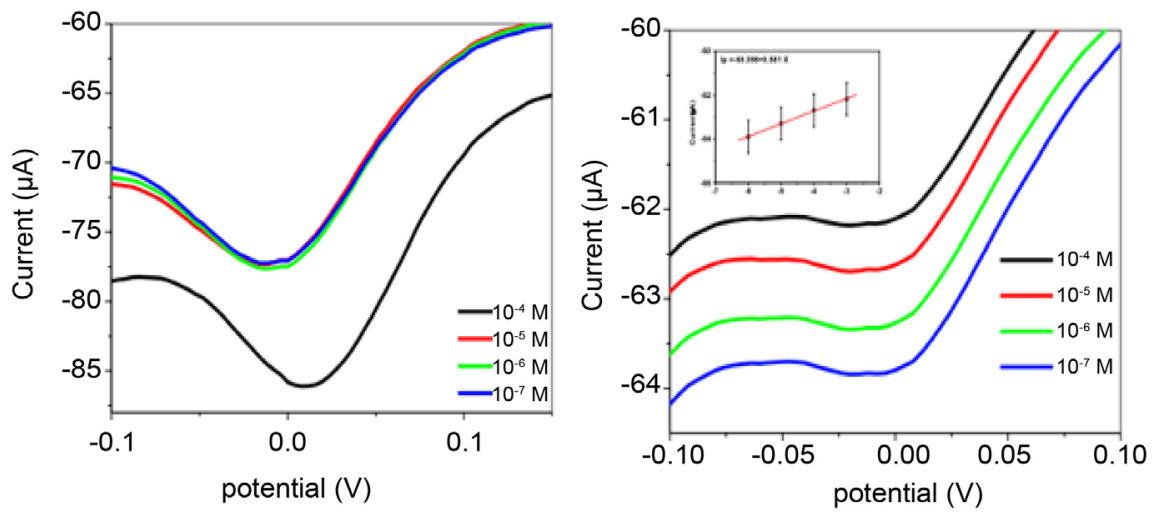

Figure 8. Differential potential voltammograms of AuNPs-modified SPCE (a) and TM-AuNPs modified SPCE (b).

\section{Conclusion}

In summary, we have successfully developed a biological and thermosensitive biosensor to simultaneously detect the behavior of proteins at different temperatures in real-time. In comparison to TM modified electrode, the TM-AuNPs modified electrode had an improved sensitivity for the amplification effect of AuNPs particles. A phase transition model analysis of TM-AuNPs films found 
that TM-AuNPs films had a phase transition interval at $<45^{\circ} \mathrm{C}, 45^{\circ} \mathrm{C}$ to $80^{\circ} \mathrm{C}$, and $>80^{\circ} \mathrm{C}$, which accommodated the temperature requirements for protein denaturation. When used to detect different concentrations of $\mathrm{Hb}$ solution, the TM-AuNPs modified SPCE had a better sensitivity in detecting the different concentrations unlike the AuNPs and TM modified SPCEs which showed no clear sensitivity towards the different $\mathrm{Hb}$ concentrations. The behavior of the TM-AuNPs SPCE in tracking the changes in protein concentration and temperature in real-time shows a good applied prospect for the study of proteins.

\section{Acknowledgements}

We appreciate Natural Science Funds of China grant No. 31771079, 61071026, supporting this project.

\section{Conflicts of Interest}

The authors declare no conflicts of interest regarding the publication of this paper.

\section{References}

[1] Faulk, W.P. and Taylor, M.G. (1971) Communication to the Editors: An Immunocolloid Method for the Electron Microscope. Immunochemistry, 8, 1081-1083. https://doi.org/10.1016/0019-2791(71)90496-4

[2] Barbosa, A.J.M., Oliveira, A.R. and Roque, A.C.A. (2018) Protein- and PeptideBased Biosensors in Artificial Olfaction. Trends in Biotechnology, 36, 1244-1258. https://doi.org/10.1016/j.tibtech.2018.07.004

[3] Cihoric, N., Savic, S., Schneider, S., et al. (2014) Prognostic Role of FGFR1 Amplification in Early-Stage Non-Small Cell Lung Cancer. British Journal of Cancer, 110, 2914-2922. https://doi.org/10.1038/bjc.2014.229

[4] Goddard, Z.R., Marín, M.J., Russell, D.A. and Searcey, M. (2020) Active Targeting of Gold Nanoparticles as Cancer Therapeutics. Chemical Society Reviews, 49, 8774-8789. https://doi.org/10.1039/D0CS01121E

[5] de la Rica, R. and Matsui, H. (2010) Applications of Peptide and Protein-Based Materials in Bionanotechnology. Chemical Society Reviews, 39, 3499-3509. https://doi.org/10.1039/B917574C

[6] Mai, H.N., Sharma, N., Shin, E.J., et al. (2018) Exposure to Far-Infrared Ray Attenuates Methamphetamine-Induced Impairment in Recognition Memory through Inhibition of Protein Kinase C $\delta$ in Male Mice: Comparison with the Antipsychotic Clozapine. Journal of Neuroscience Research, 96, 1294-1310. https://doi.org/10.1002/jnr.24228

[7] Monroy, B.Y., Sawyer, D.L., Ackermann, B.E., et al. (2018) Competition between Microtubule-Associated Proteins Directs Motor Transport. Nature Communications, 16, Article No. 1487. https://doi.org/10.1101/180935

[8] Mitra, B., Lametsch, R., Akcan, T. and Ruiz-Carrascal, J. (2018) Pork Proteins Oxidative Modifications under the Influence of Varied Time-Temperature Thermal Treatments: A Chemical and Redox Proteomics Assessment. Meat Science, 140, 134-144. https://doi.org/10.1016/j.meatsci.2018.03.011

[9] Bischof, J.C. and He, X.M. (2005) Thermal Stability of Proteins. Annals of the New 
York Academy of Sciences, 1066, 12-33.

[10] Bogahawaththa, D., Chandrapala, J. and Vasiljevic, T. (2017) Thermal Denaturation of Bovine Immunoglobulin G and Its Association with Other Whey Proteins. Food Hydrocolloids, 72, 350-357. https://doi.org/10.1016/j.foodhyd.2017.06.017

[11] Narhi, L.O., Philo, J.S., Sun, B., et al. (1999) Reversibility of Heat-Induced Denaturation of the Recombinant Human Megakaryocyte Growth and Development Factor. Pharmaceutical Research, 16, 799-807. https://doi.org/10.1023/A:1018893115557

[12] Honeychurch, K.C., Gilbert, L. and Hart, J.P. (2010) Electrocatalytic Behaviour of Citric Acid at a Cobalt Phthalocyanine-Modified Screen-Printed Carbon Electrode and Its Application in Pharmaceutical and Food Analysis. Analytical and Bioanalytical Chemistry, 396, 3103-3111. https://doi.org/10.1007/s00216-010-3534-x

[13] Gupta, P., Goyal, R.N. and Shim, Y.-B. (2015) Simultaneous Analysis of Dopamine and 5-Hydroxyindoleacetic Acid at Nanogold Modified Screen Printed Carbon Electrodes. Sensors and Actuators B: Chemical, 213, 72-81. https://doi.org/10.1016/j.snb.2015.02.066

[14] Verbeke, W. and Liu, R.D. (2014) The Impacts of Information about the Risks and Benefits of Pork Consumption on Chinese Consumers' Perception towards, and Intention to Eat Pork. Meat Science, 98, 766-772. https://doi.org/10.1016/j.meatsci.2014.07.023

[15] Tornberg, E. (2005) Effects of Heat on Meat Proteins-Implications on Structure and Quality of Meat Products. Meat Science, 70, 493-508.

https://doi.org/10.1016/j.meatsci.2004.11.021

[16] Broncano, J.M., Petrón, M.J., Parra, V., and Timón, M.L. (2009) Effects of Different Cooking Methods on Lipd Oxidation and Formation of Free Cholesterol Oxidation Products (COPs) in Latissimus dorsi Muscle of Iberian Pigs. Meat Science, 83, 431-437.

[17] Domínguez, R., Borrajo, P. and Lorenzo, J.M. (2015) The Effect of Cooking Methods on Nutritional Value of Foal Meat. Journal of Food Composition and Analysis, 43, 61-67. https://doi.org/10.1016/j.jfca.2015.04.007

[18] Lorenzo, J.M. and Dominguez, R. (2014) Cooking Losses, Lipid Oxidation and Formation of Volatile Compounds in Foal Meat as Affected by Cooking Procedure. Flavour and Fragrance Journal, 29, 240-248. https://doi.org/10.1002/ffj.3201

[19] Sheard, P.R., Nute, G.R. and Chappell, A.G. (1998) The Effect of Cooking on the Chemical Composition of Meat Products with Special Reference to Fat Loss. Meat Science, 49, 175-191. https://doi.org/10.1016/S0309-1740(97)00137-X

[20] Takemura, K., Adegoke, O., Takahashi, N., et al. (2017) Versatility of a Localized Surface Plasmon Resonance-Based Gold Nanoparticle-Alloyed Quantum Dot Nanobiosensor for Immunofluorescence Detection of Viruses. Biosensors and Bioelectronics, 89, 998-1005. https://doi.org/10.1016/j.bios.2016.10.045

[21] Lee, S.C., Jeong, Y.G., Jo, W.H., et al. (2006) Thermochromism of a Novel Organic Compound in the Solid State via Crystal-to-Crystal Transformation. Journal of Molecular Structure, 825, 70-78. https://doi.org/10.1016/j.molstruc.2006.04.025

[22] Serrano, A., Librelotto, J., Cofrades, S., Sánchez-Muniz, F.J. and Jiménez-Colmeneroa, F. (2007) Composition and Physicochemical Characteristics of Restructured Beef Steaks Containing Walnuts as Affected by Cooking Method. Meat Science, 77, 304-313. https://doi.org/10.1016/j.meatsci.2007.03.017

[23] Zhang, M., Tang, J., Mujumdar, A.S. and Wang, S. (2006) Trends in Microwave- 
Related Drying of Fruits and Vegetables. Trends in Food Science \& Technology, 17, 524-534. https://doi.org/10.1016/j.tifs.2006.04.011

[24] Frens, G. (1973) Controlled Nucleation for the Regulation of the Particle Size in Monodisperse Gold Suspensions. Nature Physical Science, 241, 20-22. https://doi.org/10.1038/physci241020a0

[25] Zou, C., Yang, B., Bin, D., et al. (2017) Electrochemical Synthesis of Gold Nanoparticles Decorated Flower-Like Graphene for High Sensitivity Detection of Nitrite. Journal of Colloid and Interface Science, 488, 135-141. https://doi.org/10.1016/j.jcis.2016.10.088

[26] Cunningham, F.E. (1970) The Effect of Heat on Egg White. World s Poultry Science Journal, 26, 783-786. https://doi.org/10.1079/WPS19700035

[27] Bertola, N.C., Bevilacqua, A.E. and Zaritzky, N.E. (1994) Heat Treatment Effect on Texture Changes and Thermal Denaturation of Proteins in Beef Muscle. Journal of Food Processing and Preservation, 18, 31-46.

https://doi.org/10.1111/j.1745-4549.1994.tb00240.x 